2

3

4

5

6

7

8

9

10

11

\title{
Boom and bust of keystone structure on coral reefs
}

\section{Shaun K Wilson ${ }^{1,2^{*}}$, James PW Robinson ${ }^{3}$, Karen Chong-Seng ${ }^{4}$, Jan Robinson ${ }^{5}$,} Nicholas AJ Graham ${ }^{3}$

5

1 Department of Biodiversity, Conservation and Attractions: Marine Science Program, Kensington, WA 6151, Australia

2 Oceans Institute, University of Western Australia, Crawley, WA 6009, Australia

3 Lancaster Environment Centre, Lancaster University, Lancaster, LA1 4YQ, UK

4 ARC Centre of Excellence for Coral Reef Studies, James Cook University, Townsville, QLD 4811, Australia

5 Ministry of Finance, Trade, Investment and Economic Planning, Victoria, Mahe, Seychelles

*Communicating author. Email: shaun.wilson@dbca.wa.gov.au

Keywords: reef resilience, coral reef ecology, disturbance ecology, structural complexity 


\section{Abstract}

Repeated bouts of coral bleaching threaten the long-term persistence of coral reefs and associated communities. Here we document the short- and long-term impacts of heatwave events on coral and fish assemblages, based on regular surveys of 18 reefs of the granitic islands of Seychelles over 23 years. Extreme heat events in 1998 and 2016 led to bleaching associated declines in coral cover, whilst between these years there was an interim period of coral recovery on some reefs. Coral decline and recovery were primarily due to changes in the cover of branching coral, particularly those from the families Acroporidae and Pocilloporidae. Surveys during the 2016 bleaching, found that $95 \%$ of the 484 Acropora and Pocillopora colonies observed were either bleached or recently dead. The extent of bleaching and subsequent mortality were best explained by a priori assessments of community susceptibility to heat stress. One year later (2017) coral cover had fallen by $70 \%$ and average coverage across the 18 reefs was at $6 \%$, similar to levels recorded in 2005 , seven years after the 1998 bleaching. Decline in coral following the 2016 bleaching coincided with reduced abundance of fish $<11 \mathrm{~cm} \mathrm{TL}$, particularly corallivores, invertivores and mixed diet feeders. These changes are likely to foreshadow more widespread loss once the habitat structure erodes. Accordingly, seven years after the 1998 bleaching, when coral skeletons and reef structure had collapsed on some reefs, abundance of both large and small bodied fish had declined. We show that fluctuation in the cover of branching coral is positively associated with changes in the abundance of small-bodied fish which contribute to ecological processes and high diversity, suggesting branching corals are a keystone structure. Increased frequency of bleaching threatens the capacity of branching corals to fully recover after disturbances, reducing the amplitude of boom bust cycles of these corals and the keystone habitat structure they provide reef fish. 


\section{Introduction}

Like many high diversity ecosystems in the tropics, coral reefs are threatened by a range of anthropogenic disturbances (Barlow et al. 2018). Of particular concern is the increasing frequency of marine heat waves that cause extensive mass bleaching and mortality of corals (Hughes et al. 2018a). These corals create the reef framework, underpinning ecological processes and services. For example, corals provide food and habitat for many of the reef associated species including highly diverse assemblages of fish (Wilson et al. 2006). These fish have crucial functional roles in terms of herbivory and bioerosion, and multispecies fisheries provide food and livelihoods for coastal communities around the world (Moberg and Folke 1999; Bellwood et al. 2004).

The physical structure, occurrence and life history traits of corals are variable, which may make some components of the coral assemblage of greater importance to reef associated fauna than others. For example, the types of corals with which fish associate varies among fish species and life history stages. Some fish feed or dwell with specific coral taxa, whilst others may associate with a broader group of corals (Cole et al. 2008; Coker et al. 2014). Branching corals appear especially important for fish as the structural complexity provided by this diverse group of corals provides refuges of numerous dimensions (Komyakova et al. 2018).

When a group of habitat forming taxa have a disproportionate contribution to ecological diversity and processes relative to their abundance, they may be considered keystone structures (Tews et al. 2004). This terminology has been used to highlight the ecological importance of large trees in terrestrial landscapes (Manning et al. 2006), and has recently been used to describe corals with specific growth forms (Kerry and Bellwood 2015). It is however difficult to definitively identify keystones as their influence may vary in different ecological settings (Menge et al. 1994). Large scale perturbations that remove candidate 
keystones, combined with temporal assessments of changes in the community, provide an opportunity to identify keystone structures. Coral reefs regularly experience disturbances, and fast-growing coral taxa may represent a 'boom' growth form that can recover habitat structure relatively quickly.

Since the 1980s there have been several global scale marine heatwaves that have caused widespread bleaching and mortality of corals. The granitic islands of Seychelles, in the Indian Ocean, have a history of exposure to severe bleaching over this time. Previous research has described the impact of mass bleaching on coral and fish assemblages on reefs in Seychelles following the 1998 heatwave (Graham et al. 2006). Subsequent surveys of the same reefs identified environmental and ecological factors that promote coral recovery and prevent reefs undergoing regime shifts (Graham et al. 2015). Here we provide detailed assessments of how the 2016 El Niño associated heatwave affected corals and associated fish on reefs in Seychelles. Based on long-term assessments of reef communities that span the major bleaching events in 1998 and 2016, and an intervening period of recovery, we identify the change in abundance of branching corals as the major cause of temporal change in coral cover and habitat structure. We then assess how periods of decline and increase in branching coral cover have influenced fish assemblages to investigate whether these corals are keystone structures on coral reefs.

\section{Methods}

Benthic and fish surveys of 18 Seychelles reefs were initially undertaken in 1994, with subsequent surveys in 2005, 2008, 2011, 2014 and 2017. The 18 reefs were founded on habitats of either granitic, contiguous carbonate or patches surrounded by sand or rubble. Six 
of the reefs were within no-take marine reserves, that have been in place since the 1970s and are managed by the government in Seychelles (Jennings et al. 1996).

At each of the 18 reefs the abundance and size (total length, TL) of fish $>7 \mathrm{~cm}$ was recorded from 134 non-cryptic, diurnally active species observed within $154 \mathrm{~m}^{2}$ replicate areas $(7 \mathrm{~m}$ radius). The diver conducting fish surveys calibrated size estimates of fish by estimating and confirming the size of plastic pipes at the start of each survey day, with mean error within $\sim 3 \%$ (Graham et al. 2007). All large mobile fish were recorded first, before a systematic search of smaller site attached species. Count areas were located at the base of reef slopes at 2-9m depth. In 1994, 2005 and 2008 there were 16 replicate areas surveyed at each of the 18 reefs and in 2011, 2014 and 2017 eight replicate areas per reef. Average values were calculated from the number of areas surveyed at each reef to account for differences in sampling intensity over time.

The structural complexity of each replicate area was scored on a scale between 0 and 5 , where areas with 0 structure were sandy or rubble substrate with no vertical relief and areas that scored 5 were exceptionally complex, with numerous caves and overhangs (Polunin and Roberts 1993). The percent cover of coral and coral growth forms (branching, massive, encrusting, tabular) within each replicate area was estimated from a plan view of the area, the coral forms being based on broad growth forms described by Veron (1986). In addition to plan view surveys, $10 \mathrm{~m}$ line intercept transects were carried out in each area from 2008. Line intercept transects recorded percent cover of coral to the genera level and comparisons between this technique with plan view surveys found estimates of coral cover from the two techniques were very similar (Wilson et al. 2007, 2012).

Reefs were also categorised as either recovering or regime shifted based on temporal trends in coral and macroalgal cover (Graham et al. 2015). Recovering reefs had higher coral than 
macroalgal cover in 2011, and an increase in coral cover between 2005 and 2011. Conversely

117 regime shifted reefs had higher macroalgal than coral cover in 2011 , with increasingly dissimilar benthic communities from 1994, characterised by rising coverage of macroalgae.

Heat stress around Seychelles reefs reached 4 degree heat weeks (DHW) in January 2016, rapidly increased in April and peaked at 11.4 DHW in May

(http://coralreefwatch.noaa.gov/vs/index.php). The extent of coral bleaching was assessed at 16 of the 18 regularly surveyed reefs between May $19^{\text {th }}$ and $1^{\text {st }}$ June 2016 , at the height of thermal stress in the region. At each reef the plan view technique was used to estimate the percent cover of healthy, bleached and recently dead corals within eight areas of the same replicate area all coral colonies along a $10 \mathrm{~m}$ line intercept transect were also identified to genus and status recorded as either healthy, bleached or recently dead. For both plan view

\section{Statistical analyses}

We assessed spatial variation in coral bleaching and temporal variation in coral community composition using generalized linear models (GLMs). Using site-level estimates of bleaching, mortality, and healthy coral cover from surveys conducted in 2016, we fitted separate GLMs for coral bleaching, coral mortality and healthy coral cover, each with site as a covariate and quasibinomial distributed errors. We assessed evidence for spatial variation in bleaching impacts using likelihood ratio tests which weighed model support for the sitecovariate model relative to a null, intercept-only model. For all three bleaching models, fits were considerably improved by inclusion of the site covariate $(\mathrm{p}<0.001)$. Next, we 
examined temporal trends in coral cover from 2005-2017 for each regime state (regime-

shifted or recovering). GLMs were fit separately to total hard coral cover, massive cover, branching cover, and structural complexity estimates (4 total models), and we assessed support for linear or non-linear relationships by comparing GLMs with generalised additive models (GAMs) with similar model structures. Temporal trends were modelled with survey year and regime state (recovering or regime shifted) as interacting fixed effects, and random effect structures which accounted for covariance with sites. Models were fitted with Poisson error distributions, except structural complexity which was fitted with Gamma error

GAMs were used to identify which environmental variables best predicted the extent of coral 
2016 and mortality calculated as ((Cover 2014 - Cover 2017)/Cover 2014). Reef level variables included in analyses were: susceptibility of the coral community to heat stress, water quality, depth, wave exposure, percent coral cover in 2014 , if the reef was in a no-take marine reserve and habitat type (patch, carbonate or granite). Analyses where mortality was the dependant variable also included the extent of bleaching in May 2016. Coral susceptibility for each reef was based on the coral community composition in 2014 and genera-specific bleaching response data from the western Indian Ocean (McClanahan et al. 2007). Coral communities with a high susceptibility to bleaching had values close to 1 whilst those with low bleaching susceptibilities had values approaching 0 . Water quality was measured as the mean percentage of nitrogen in 10 Sargassum fonds collected from each reef in 2014 (Graham et al. 2015), higher values being indicative of poorer water quality and greater propensity of corals to bleaching (Wooldridge 2016). The extent of coral bleaching is linked to water depth (McClanahan et al. 2007; Moore et al. 2012), which we measured as the mean depth across replicate reef areas within a reef. Wave exposure was considered in analyses as it may increase flushing of reefs, ameliorating the effects of heat stress (Shedrawi et al. 2017). Exposure at each reef (measured in Joules) was calculated from fetch, wind speed and direction between 1998 and 2011 (Graham et al. 2015). Finally, we considered the effect of no-take areas, which reduce other anthropogenic pressures and thereby potentially increase reef resilience (Mellin et al. 2016). All combinations of three or fewer explanatory variables were considered in analyses and the best models selected based on lowest AIC scores and fewest variables (Fisher et al. 2018). The relative importance of variables was also calculated by summing AIC weights (Burnham and Anderson 2003). The analysis was restricted to the 15 reefs where information on all variables was available.

To assess the effect of coral loss on fish assemblages we examined the relationship between percent cover of branching coral and abundance of fish of different size and diet. Fish were 
placed into $5 \mathrm{~cm}$ size classes and broad diet categories (Corallivores, Herbivores, Invertivores Piscivores, Planktivores and Mixed) based on information in Fishbase (Froese and Pauly 2012). Changes in abundance of different sized fish from each dietary category were also assessed with respect to periods of coral decline (1994 to 2005 and 2014 to 2017) and coral increase (2005 to 2014). For these assessments, the average density of fish per $154 \mathrm{~m}^{2}$ count area was calculated for each dietary size class at each reef over each time period. Temporal changes in fish abundance were then calculated using reefs as replicates and significant declines or increases of each fish group were determined by $95 \%$ confidence intervals.

\section{Results}

\section{Long-term trends in coral}

A year after the 2016 bleaching event the average coral cover across 18 reefs, that had been consistently monitored since 1994, was $6 \pm 1$ (SE) \% (Fig 1a). This represented a decline of $70 \%$ in total coral cover from $2014(20 \pm 3 \%)$, which was similar on both recovering $(70 \%)$ and regime-shifted (74\%) reefs. The decline in coral cover between 2014 and 2017 is also similar to the $68 \%$ change in coral cover between 1994 and 2005 following the 1998 bleaching. In both instances the loss of coral following bleaching was primarily due to mortality of corals with a branching growth form. Temporal trends of branching and total coral cover were very similar, particularly on recovering reefs where cover gradually increased between 2005 and 2014, before the rapid fall in 2017 (Fig 1b). Indeed, major fluctuations in coral cover between 2005 and 2017 can be directly attributed to changes in the percent cover of branching corals. The gain in cover of branching cover between 2005 and 2014 was effectively nullified by decline of these corals after bleaching in 2016 (Fig 2).

Percent cover of massive corals has also declined since surveys began in 1994 (Fig 1c), 
though changes are not as dramatic as for branching corals, and average cover of massive corals remained at $5 \pm 1$ (SE)\% on recovering reefs, even after the 2016 bleaching event.

Temporal changes in the cover of different coral growth forms were associated with changes in coral genera between 2011 and $2017\left(\mathrm{~F}_{3,62}=3.66, \mathrm{P}=0.005\right)$ and among reef types $\left(\mathrm{F}_{1,62}=\right.$ $15.33, \mathrm{P}<0.001)$. Recovery on granitic reefs was associated with an increase in the abundance of branching Pocillopora and encrusting Favia, Acanthastrea and Montipora between 2008 and 2014. However, the recovery on carbonate and patch reefs was characterised by Acropora, Echinopora, massive Lobophylia /Goniopora, and encrusting Galaxea (Fig. 3). Coral cover on regime-shifted reefs was low and characterised by Fungia and branching Porites, especially on carbonate reefs.

Like coral cover, the structural complexity of Seychelles reefs has declined since 1994, though temporal trajectories differed between reef states (Fig 1d). On regime-shifted reefs structure gradually declined between 2005 and 2011, whilst on recovering reefs it has remained relatively stable. On both recovering and regime-shifted reefs structural complexity did not change greatly between 2014 and 2017.

\section{6 bleaching event}

Plan view assessments of bleaching at 16 reefs around Seychelles' granitic islands in MayJune 2016 found that $80 \%$ of coral had bleached or recently died, and on 15 of these reefs $>50 \%$ of the estimated coral cover had bleached (Fig 4a). Coverage of branching corals was high compared to other growth forms ( $28 \%$ ), however $63 \%$ of these corals where bleached and 30\% had recently died (Fig 4b). Similarly, almost all tabular corals had bleached or died and only $2 \%$ of these corals appeared healthy. Conversely, although $68 \%$ of the massive coral coverage (10\%) had bleached few of these corals had recently died and the majority of encrusting corals were healthy. Assessments of bleaching at the colony level were similar to 

those from plan views with $82 \%$ of the 1194 colonies being bleached or recently dead (Fig 4c). Of the Acropora (369) and Pocillopora (99) colonies surveyed more than $94 \%$ were bleached or recently dead, whilst $26 \%$ of Porites colonies (255), which were among the most common massive genera, were considered healthy.

Spatial variation in the extent of coral bleaching in 2016 was best explained by a model that included susceptibility of the coral community to heat stress, water quality and wave exposure (Table 1). Sites with low to medium wave exposure, a high proportion of genera susceptible to bleaching, and higher nitrogen content in macroalgal samples tended to have a higher percentage of bleached corals (Fig 5a). The extent of coral loss between 2014 and 2017 was also related to bleaching susceptibility, changes in coral cover being less pronounced on reefs with high abundance of thermally resistant taxa (Fig 5b).

\section{Branching coral and fish assemblages}

Changes in branching coral cover affected fish from all dietary categories, particularly those that are small-bodied. Indeed abundance of fish with estimated total lengths 8 to $11 \mathrm{~cm}$ was positively correlated with branching coral cover for all dietary categories, although this relationship was weaker among larger fish (Fig 6). The relationship was especially strong among small-bodied corallivores, changes in percent cover of branching corals accounting for $50 \%$ of the variation in coral feeding fish 8 to $11 \mathrm{~cm}$. Accordingly abundance of small-bodied corallivores declined during periods when coral bleaching had caused loss of branching corals (1994 to 2005 and 2014 to 2017), but increased during the intermediate period (2005 to 2014), when branching coral cover increased on some reefs.

Decline in small corallivore abundance was greatest between 2014 and 2017, following the 2016 bleaching event, However, declines in abundance of small planktivores and herbivores ( 8 to $11 \mathrm{~cm}$ ) was greatest between 1994 and 2005, seven years after the 1998 bleaching event, 
whilst changes in small piscivores were negligible following both bleaching events. There were however significant changes in medium sized $(26$ to $30 \mathrm{~cm})$ piscivores, their numbers increasing a year after the 2016 bleaching, but this same size category declined seven years after the 1998 bleaching. Similarly, many medium sized herbivores declined in abundance between 1994 and 2005, yet the abundance of these medium sized herbivores increased following the bleaching in 2016.

\section{Discussion}

Over the past 20 years the granitic islands of Seychelles have experienced two major heat stress events that have caused widespread coral bleaching and mortality. The decline in percent coral cover following these two events, and recovery during the intervening years, has been predominantly driven by fluctuations in the cover of branching corals. Many of the taxa that have branching morphology have life history traits that favour wide dispersal and rapid growth (Pratchett et al. 2015), characteristics that allow rapid recovery following disturbance (Darling et al. 2012). However, these taxa are also highly susceptible to a range of environmental pressures including heat stress (Hoey et al. 2016). As a consequence, coverage of branching corals on reefs can undergo dramatic and rapid changes (Goreau et al 2000), reflecting periods of boom and bust, that have concomitant impacts on reef associated fish assemblages. This affords some level of stability in cover over longer time frames and branching corals have dominated reef assemblages over the past 1.8 million years (Renema et al. 2016). The onset of the Anthropocene has however coincided with the decline of these corals over large parts of the Caribbean (Greenstein et al. 1998; Cramer et al. 2012) and an inshore reef on the GBR (Roff et al. 2013). Recent bleaching at global scales has extended this effect to many of the world's reefs (Hughes et al. 2018a, 2018b) 
287 Long-term data from the Seychelles, through two major disturbances and an extended period 288 of recovery, highlight the potential role of branching coral as a keystone structure on coral

289 reefs. Declines in coral and the flow-on impacts to associated communities affect the ecosystems services provided by reefs (Pratchett et al. 2014; Robinson et al. 2018). For example, branching corals are especially important for maintaining high rates of reef growth and protecting coastlines from rising sea levels (Perry et al. 2015, 2018). Percent cover of branching corals is also positively correlated with structural complexity; an important determinant of reef fish diversity (Graham and Nash 2013). Here we clearly demonstrate that these corals are especially important habitat for a trophically diverse group of small bodied fish, whose abundance closely tracks changes in branching coral cover. Accordingly loss of coral following the 1998 bleaching was associated with a decline in both small-bodied taxa and species richness of fish in the Seychelles (Graham et al. 2006). Moreover, loss of branching corals is associated with changes in prey availability and predator diets that alter how energy is transferred within coral reef food webs (Hempson et al. 2018). Many larger bodied predators are also closely associated with the reef during the early stages of their benthic lives, often sheltering among the branches of coral colonies (Wen et al. 2013). These species are often important to reef fisheries, and changes in branching coral cover is likely to have flow-on implications for future stocks of these taxa (Graham et al. 2007).

The timing of our post-bleaching surveys allowed assessments of both long and short-term changes to branching coral cover to fish assemblages. In 2005, seven years after declines of live branching coral, the reef structure had started to collapse on many reefs (Graham et al. 2006). Accordingly, we documented declines in both small and medium sized fish from piscivorous and herbivorous feeding guilds. Many fish in these guilds have no obvious reliance on live coral but may take shelter or feed among the branching skeletons (Pratchett et 

body size with a mixed diet, which is consistent with theories that generalists benefit from disturbance (Bellwood et al. 2006). Conversely, a year after the 2016 bleaching, coral cover had declined by $70 \%$ yet only the smaller bodied fish were negatively affected. Indeed, abundance of medium-sized predators had increased during this short time frame, suggesting these meso-predators have contributed to the demise of smaller bodied prey. The apparent short-term increase in predators is unlikely to be sustainable, especially if reef structure collapses and there is a shift to macroalgal dominated states (Hempson et al. 2018).

\section{Conclusion}

Increased frequency of heat stress events may have dire consequences for the persistence of branching corals. In Seychelles, coral cover fell by 90\% soon after the 1998 event (Goreau et al. 2000) and although some of these reefs recovered, others underwent a regime shift and are now dominated by fleshy macroalgae (Graham et al. 2015). It took more than 10 years for those reefs that recovered to attain levels of coral cover similar to that recorded prebleaching. Severe bleaching events are now expected every 6 years (Hughes et al. 2018a), seriously compromising the capacity of corals to recover and leading to a gradual ratchetting down of coral cover (Birkeland 2004). This will gradually diminish the amplitude of boom bust cycles in branching coral cover and the influence they have on reef ecosystems.

The sensitivity of branching taxa to bleaching has led to suggestions that coral assemblages will be increasingly characterised by thermally tolerant taxa (van Woesik et al. 2011). Indeed, we found both coral bleaching and mortality were directly related to the susceptibility of the coral community to heat stress. The prominence of massive coral colonies on Seychelles reefs in surveys after bleaching indicates that some corals have persisted through the 1998 and 2016 events. Although relatively slow growing compared to branching growth forms 
(Pratchett et al. 2015) these massive corals are important for maintaining positive reef accretion post-bleaching (Januchowski-Hartley et al. 2017) and are an important component of reef structure at seascape scales (Darling et al. 2017). The gradual decline of massive corals is of concern, as these corals are expected to take much longer to recover than branching morphologies (Pratchett et al. 2015). Massive coral colonies are however unlikely to shelter the same abundance and diversity of fish as branching colonies of similar size (Holbrook et al. 2002a), emphasizing the importance of branching corals to fish assemblages.

Branching corals are clearly important habitat for many fish on reefs within the Seychelles, and other parts of the world (Holbrook et al. 2002b; Wilson et al. 2008; Coker et al. 2014; Komyakova et al. 2018). Moreover, diversity of coral associated invertebrates is highest in colonies with complex branching morphology, with many species inhabiting branching pocilloporids and acroporids (Stella et al. 2011). As a consequence, spatial and temporal variation in the cover of branching corals is a key determinant of diversity, size structure and trophodynamics on coral reefs. That branching corals are also major contributors to reef growth and accretion emphasises their ecological and geomorphological roles across multiple processes and suggests these corals are keystone structures. Boom and bust fluctuations in the amount of branching corals are therefore expected to alter ecological and physical processes, their long-term demise having flow-on effects for the ecosystem services provide by coral reefs.

\section{Acknowledgements}

We thank Seychelles Fishing Authority, Seychelles Marine Parks Authority, Nature Seychelles, and Global Vision International for field assistance. The project was funded via grants from the Leverhulme Trust, Australian Research Council, and the Royal Society. Data on coral and fish assemblages in 1994 was collected and kindly provided by Simon Jennings. Rebecca Fisher provided statistical advice. 


\section{Conflicts of interest}

On behalf of all authors, the corresponding author states that there is no conflict of interest.

\section{References}

Barlow J, França F, Gardner TA, Hicks CC, Lennox GD, Berenguer E, Castello L, Economo EP, Ferreira J, Guenard B (2018) The future of hyperdiverse tropical ecosystems. Nature 559:517-526

Bellwood DR, Hoey AS, Ackerman JL, Depczynski M (2006) Coral bleaching, reef fish community phase shifts and the resilience of coral reefs. Glob Change Biol 12:1587-1594

Bellwood DR, Hughes TP, Folke C, Nyström M (2004) Confronting the coral reef crisis. Nature 429:827-833

Birkeland C (2004) Ratcheting down the coral reefs. BioScience 54:1021-1027

Brandl SJ, Goatley CH, Bellwood DR, Tornabene L (2018) The hidden half: ecology and evolution of cryptobenthic fishes on coral reefs. Biol Rev 93:1846-1873

Burnham KP, Anderson DR (2003) Model Selection and Multimodel Inference: A Practical Information-Theoretic Approach. Springer Science \& Business Media,

Coker DJ, Wilson SK, Pratchett MS (2014) Importance of live coral habitat for reef fishes. Rev Fish Biol Fish 24:89-126

Cole AJ, Pratchett MS, Jones GP (2008) Diversity and functional importance of coral-feeding fishes on tropical coral reefs. Fish Fish 9:286-307

Cramer KL, Jackson JBC, Angioletti CV, Leonard-Pingel J, Guilderson TP (2012) Anthropogenic mortality on coral reefs in Caribbean Panama predates coral disease and bleaching. Ecol Lett 15:561-567

Darling ES, Alvarez-Filip L, Oliver TA, McClanahan TR, Côté IM (2012) Evaluating life-history strategies of reef corals from species traits. Ecol Lett 15:1378-1386

Darling ES, Graham NAJ, Januchowski-Hartley FA, Nash KL, Pratchett MS, Wilson SK (2017) Relationships between structural complexity, coral traits, and reef fish assemblages. Coral Reefs 36:561-575

Fisher R, Wilson SK, Sin TM, Lee AC, Langlois TJ (2018) A simple function for full-subsets multiple regression in ecology with R. Ecol Evol 8:6104-6113

Froese R, Pauly D (2012) FishBase. http://www.fishbase.org,

Goreau T, McClanahan T, Hayes R, Strong A (2000) Conservation of Coral Reefs after the 1998 Global Bleaching Event. Conserv Biol 14:5-15

Graham NA, Wilson SK, Jennings S, Polunin NV, Bijoux JP, Robinson J (2006) Dynamic fragility of oceanic coral reef ecosystems. Proc Natl Acad Sci 103:8425-8429 
Graham NAJ, Jennings S, MacNeil MA, Mouillot D, Wilson SK (2015) Predicting climate-driven regime shifts versus rebound potential in coral reefs. Nature 518:94-97

Graham NAJ, Nash KL (2013) The importance of structural complexity in coral reef ecosystems. Coral Reefs 32:315-326

Graham NAJ, Wilson SK, Jennings S, Polunin NVC, Robinson J, Bijoux JP, Daw TM (2007) Lag Effects in the Impacts of Mass Coral Bleaching on Coral Reef Fish, Fisheries, and Ecosystems. Conserv Biol 21:1291-1300

Greenstein BJ, Curran HA, Pandolfi JM (1998) Shifting ecological baselines and the demise of Acropora cervicornis in the western North Atlantic and Caribbean Province: a Pleistocene perspective. Coral Reefs 17:249-261

Hempson TN, Graham NA, MacNeil MA, Hoey AS, Wilson SK (2018) Ecosystem regime shifts disrupt trophic structure. Ecol Appl 28:191-200

Hoey A, Howells E, Johansen J, Hobbs J-P, Messmer V, McCowan D, Wilson S, Pratchett M (2016) Recent advances in understanding the effects of climate change on coral reefs. Diversity 8:12

Holbrook SJ, Brooks AJ, Schmitt RJ (2002a) Variation in structural attributes of patch-forming corals and in patterns of abundance of associated fishes. Mar Freshw Res 53:1045-1053

Holbrook SJ, Brooks AJ, Schmitt RJ (2002b) Predictability of fish assemblages on coral patch reefs. Mar Freshw Res 53:181-188

Hughes TP, Anderson KD, Connolly SR, Heron SF, Kerry JT, Lough JM, Baird AH, Baum JK, Berumen ML, Bridge TC (2018a) Spatial and temporal patterns of mass bleaching of corals in the Anthropocene. Science 359:80-83

Hughes TP, Kerry JT, Baird AH, Connolly SR, Dietzel A, Eakin CM, Heron SF, Hoey AS, Hoogenboom MO, Liu G, McWilliam MJ, Pears RJ, Pratchett MS, Skirving WJ, Stella JS, Torda G (2018b) Global warming transforms coral reef assemblages. Nature 556:492

Januchowski-Hartley FA, Graham NAJ, Wilson SK, Jennings S, Perry CT (2017) Drivers and predictions of coral reef carbonate budget trajectories. Proc R Soc B Biol Sci 284:20162533

Jennings S, Marshall SS, Polunin NV (1996) Seychelles' marine protected areas: comparative structure and status of reef fish communities. Biol Conserv 75:201-209

Kerry JT, Bellwood DR (2015) Do tabular corals constitute keystone structures for fishes on coral reefs? Coral Reefs 34:41-50

Komyakova V, Jones GP, Munday PL (2018) Strong effects of coral species on the diversity and structure of reef fish communities: A multi-scale analysis. PLOS ONE 13:e0202206

Manning AD, Fischer J, Lindenmayer DB (2006) Scattered trees are keystone structures-implications for conservation. Biol Conserv 132:311-321

McClanahan TR, Ateweberhan M, Graham NAJ, Wilson SK, Sebastian CR, Guillaume MM, Bruggemann JH (2007) Western Indian Ocean coral communities: bleaching responses and susceptibility to extinction. Mar Ecol Prog Ser 337:1-13 
Mellin C, Aaron MacNeil M, Cheal AJ, Emslie MJ, Julian Caley M (2016) Marine protected areas increase resilience among coral reef communities. Ecol Lett 19:629-637

Menge BA, Berlow EL, Blanchette CA, Navarrete SA, Yamada SB (1994) The keystone species concept: variation in interaction strength in a rocky intertidal habitat. Ecol Monogr 64:249286

Moberg F, Folke C (1999) Ecological goods and services of coral reef ecosystems. Ecol Econ 29:215233

Moore JAY, Bellchambers LM, Depczynski MR, Evans RD, Evans SN, Field SN, Friedman KJ, Gilmour JP, Holmes TH, Middlebrook R, Radford BT, Ridgway T, Shedrawi G, Taylor H, Thomson DP, Wilson SK (2012) Unprecedented Mass Bleaching and Loss of Coral across $12^{\circ}$ of Latitude in Western Australia in 2010-11. PLoS ONE 7:e51807

Perry CT, Alvarez-Filip L, Graham NA, Mumby PJ, Wilson SK, Kench PS, Manzello DP, Morgan KM, Slangen AB, Thomson DP (2018) Loss of coral reef growth capacity to track future increases in sea level. Nature 558:396-400

Perry CT, Murphy GN, Graham NAJ, Wilson SK, Januchowski-Hartley FA, East HK (2015) Remote coral reefs can sustain high growth potential and may match future sea-level trends. Sci Rep $5: 18289$

Polunin NVC, Roberts CM (1993) Greater biomass and value of target coral-reef fishes in two small Caribbean marine reserves. Mar Ecol-Prog Ser 100:167-167

Pratchett M, Anderson K, Hoogenboom M, Widman E, Baird A, Pandolfi J, Edmunds P, Lough J (2015) Spatial, Temporal and Taxonomic Variation in Coral Growth?Implications for the Structure and Function of Coral Reef Ecosystems. In: Hughes R., Hughes D., Smith I., Dale A. (eds) Oceanography and Marine Biology. CRC Press, pp 215-296

Pratchett MS, Hoey AS, Wilson SK (2014) Reef degradation and the loss of critical ecosystem goods and services provided by coral reef fishes. Curr Opin Environ Sustain 7:37-43

Pratchett MS, Munday P, Wilson SK, Graham NA, Cinner JE, Bellwood DR, Jones GP, Polunin NV, McClanahan TR (2008) Effects of climate-induced coral bleaching on coral-reef fishes. Ecol Econ Consequences Oceanogr Mar Biol Annu Rev 46:251-296

Renema W, Pandolfi JM, Kiessling W, Bosellini FR, Klaus JS, Korpanty C, Rosen BR, Santodomingo N, Wallace CC, Webster JM (2016) Are coral reefs victims of their own past success? Sci Adv 2:e1500850

Robinson JPW, Wilson SK, Robinson J, Gerry C, Lucas J, Assan C, Govinden R, Jennings S, Graham NAJ (2018) Productive instability of coral reef fisheries after climate-driven regime shifts. Nat Ecol Evol 1

Roff G, Clark TR, Reymond CE, Zhao J, Feng Y, McCook LJ, Done TJ, Pandolfi JM (2013) Palaeoecological evidence of a historical collapse of corals at Pelorus Island, inshore Great Barrier Reef, following European settlement. Proc R Soc B 280:20122100

Shedrawi G, Falter JL, Friedman KJ, Lowe RJ, Pratchett MS, Simpson CJ, Speed CW, Wilson SK, Zhang Z (2017) Localised hydrodynamics influence vulnerability of coral communities to environmental disturbances. Coral Reefs 36:861-872 
Stella J, Pratchett MS, Hutchings P, Jones GP (2011) Coral-associated invertebrates: diversity, ecological importance and vulnerability to disturbance. Oceanogr Mar Biol Annu Rev 49:43104

Tews J, Brose U, Grimm V, Tielbörger K, Wichmann MC, Schwager M, Jeltsch F (2004) Animal species diversity driven by habitat heterogeneity/diversity: the importance of keystone structures. J Biogeogr 31:79-92

Veron JEN (1986) Corals of Australia and the Indo-pacific. Angus \& Robertson Sydney,

Wen CKC, Pratchett MS, Almany GR, Jones GP (2013) Patterns of recruitment and microhabitat associations for three predatory coral reef fishes on the southern Great Barrier Reef, Australia. Coral Reefs 32:389-398

Wilson SK, Fisher R, Pratchett MS, Graham NAJ, Dulvy NK, Turner RA, Cakacaka A, Polunin NVC, Rushton SP (2008) Exploitation and habitat degradation as agents of change within coral reef fish communities. Glob Change Biol 14:2796-2809

Wilson SK, Graham NAJ, Fisher R, Robinson J, Nash K, Chong-Seng K, Polunin NVC, Aumeeruddy R, Quatre R (2012) Effect of Macroalgal Expansion and Marine Protected Areas on Coral Recovery Following a Climatic Disturbance: Macroalgae, MPAs, and Coral Recovery. Conserv Biol 26:995-1004

Wilson SK, Graham NAJ, Polunin NVC (2007) Appraisal of visual assessments of habitat complexity and benthic composition on coral reefs. Mar Biol 151:1069-1076

Wilson SK, Graham NAJ, Pratchett MS, Jones GP, Polunin NVC (2006) Multiple disturbances and the global degradation of coral reefs: are reef fishes at risk or resilient? Glob Change Biol $12: 2220-2234$

van Woesik R, Sakai K, Ganase A, Loya Y (2011) Revisiting the winners and the losers a decade after coral bleaching. Mar Ecol Prog Ser 434:67-76

Wood SN (2017) Generalized additive models: an introduction with R. Chapman and Hall/CRC,

Wooldridge SA (2016) Excess seawater nutrients, enlarged algal symbiont densities and bleaching sensitive reef locations: 1. Identifying thresholds of concern for the Great Barrier Reef, Australia. Mar Pollut Bull 
505 Table 1. Best models for predicting bleaching and mortality of corals following heat stress in 506 2016. Variables considered in models were: Susceptibility of the coral community to

507 bleaching in 2014 based on bleaching response of different genera (McClanahan et al. 2007);

508 Water Quality measured as $\% N$ of macroalgae collected in 2014; Depth; Exposure based on 509 fetch, wind speed and direction (Graham et al. 2015); Cover of coral in 2014; if reefs were

510 Fished or no-take reserves; and Habitat type. Bleaching of corals in 2016 was also

511 considered in analyses to predict coral mortality.

\begin{tabular}{llllll}
\hline \multirow{3}{*}{ Bleaching } & Predictors & $\Delta \mathrm{AIC}$ & $\mathrm{AIC}$ wt & edf & $\mathrm{R}^{2}$ \\
& $\begin{array}{l}\text { Susceptibility }+\% \mathrm{~N}+\text { Exposure } \\
\text { MN + Exposure + Habitat }\end{array}$ & 0.00 & $0 . .65$ & 6.9 & 0.63 \\
& & 1.20 & 0.35 & 7.0 & 0.46 \\
& & & & \\
Mortality & 0.00 & 0.23 & 5.0 & 0.71 \\
& Susceptibility + Fished & 0.57 & 0.18 & 3.0 & 0.37 \\
& Susceptibility & 0.89 & 0.15 & 2.0 & 0.34 \\
& Susceptibility + Exposure & 2.10 & 0.08 & 3.1 & 0.35
\end{tabular}



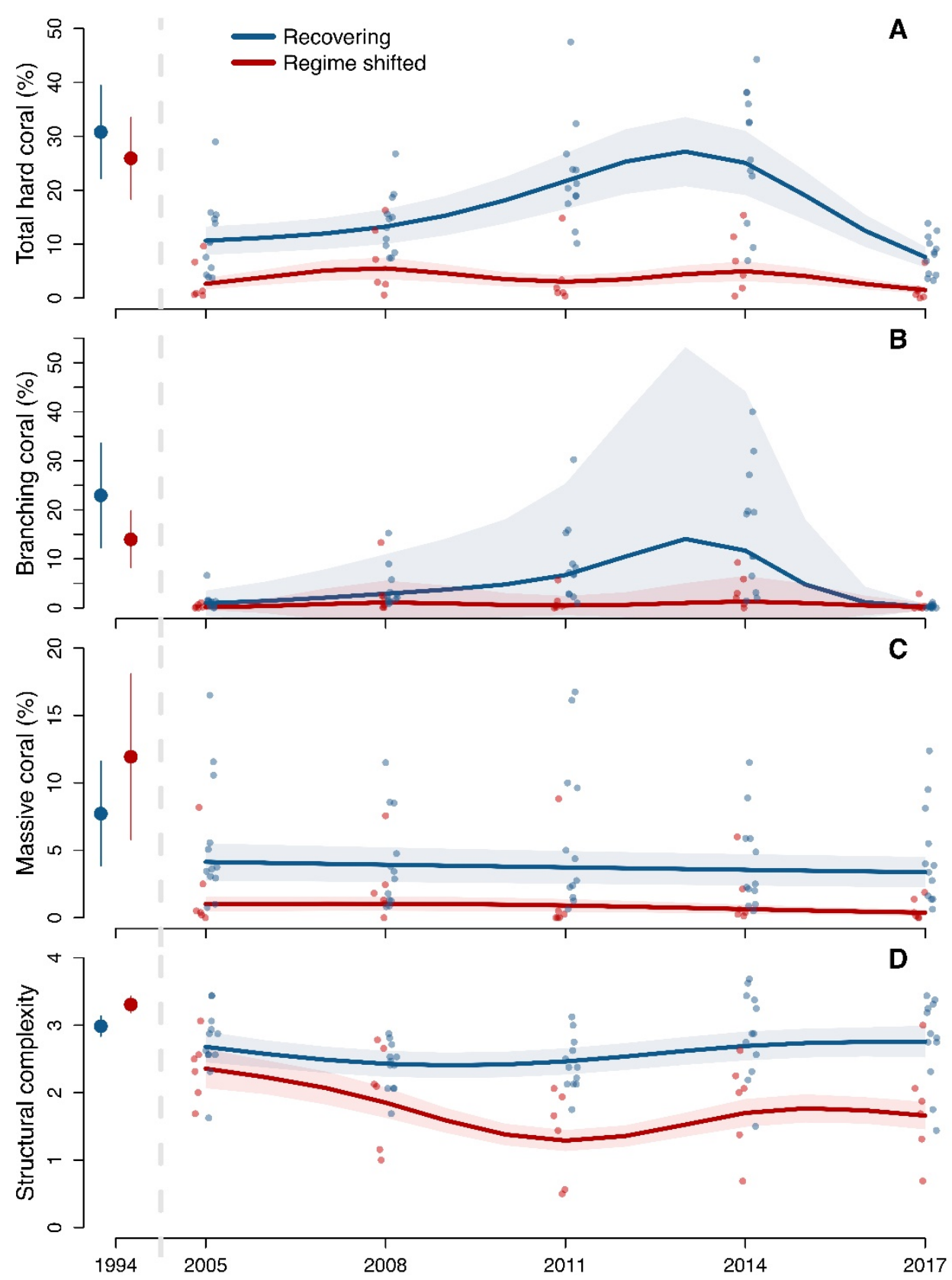

515 Fig 1. Temporal change in coral cover and structural complexity from 1994-2017. Lines are

516 predictions from GAMs of total coral cover (A), branching cover (B), massive cover (C), and

517 structural complexity (D), shaded with 2 standard errors (SE). Points are mean cover

518 estimates ( $\pm 2 \mathrm{SE}$ ), jittered to separate regime shifted (red) from recovering (blue) reefs.

519 Models were fitted with interacting survey year and regime state covariates, and random effect terms for reef site. 


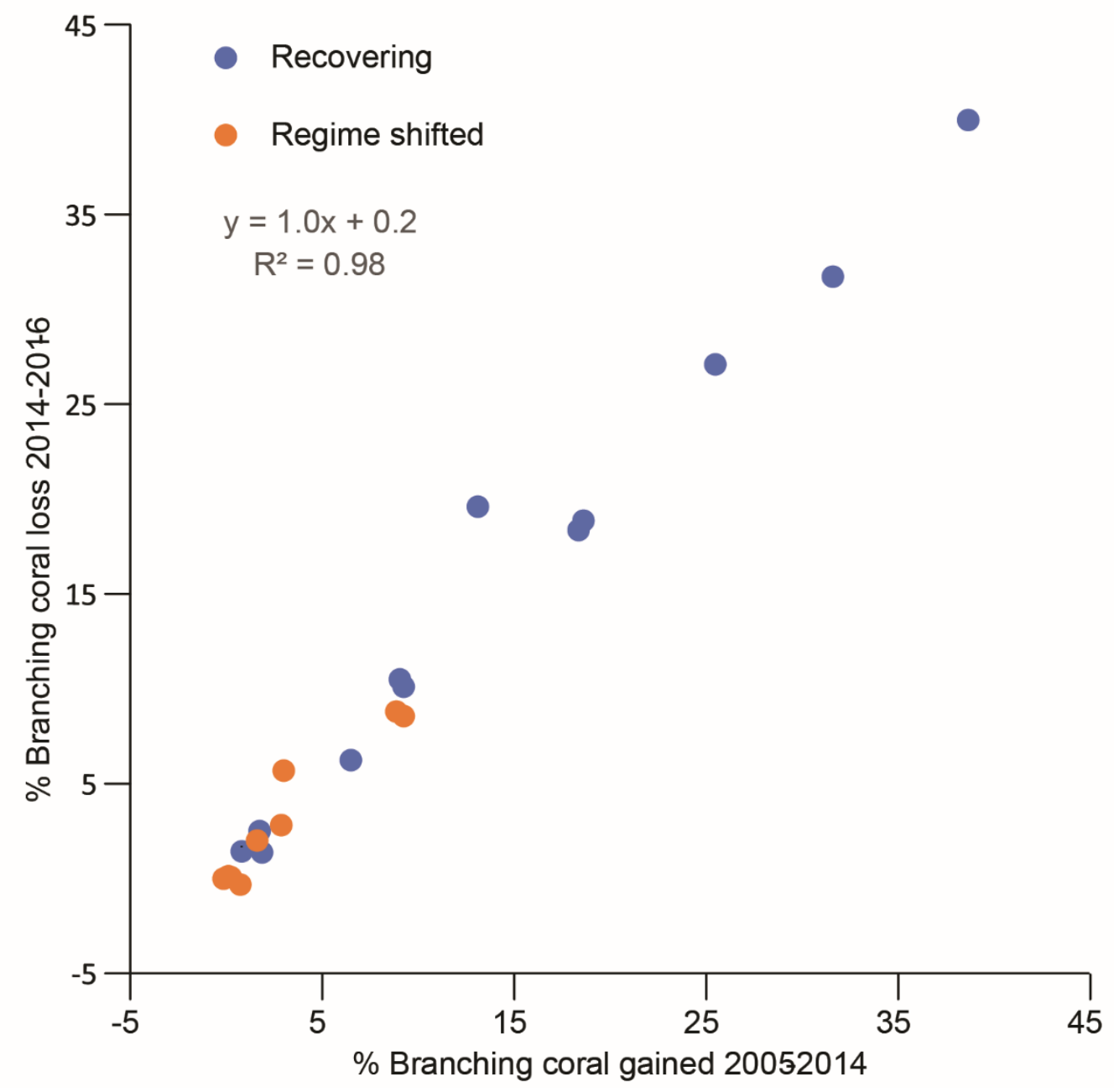

21

Fig 2. Extent of change in branching coral cover during periods of recovery (2005-2014) and 523 decline (2014-2017). Correlation co-efficient calculated from six regime shifted (orange) and 524 twelve recovering (blue) reefs. 
- Carbonate

- Granite

$\diamond$ Patch

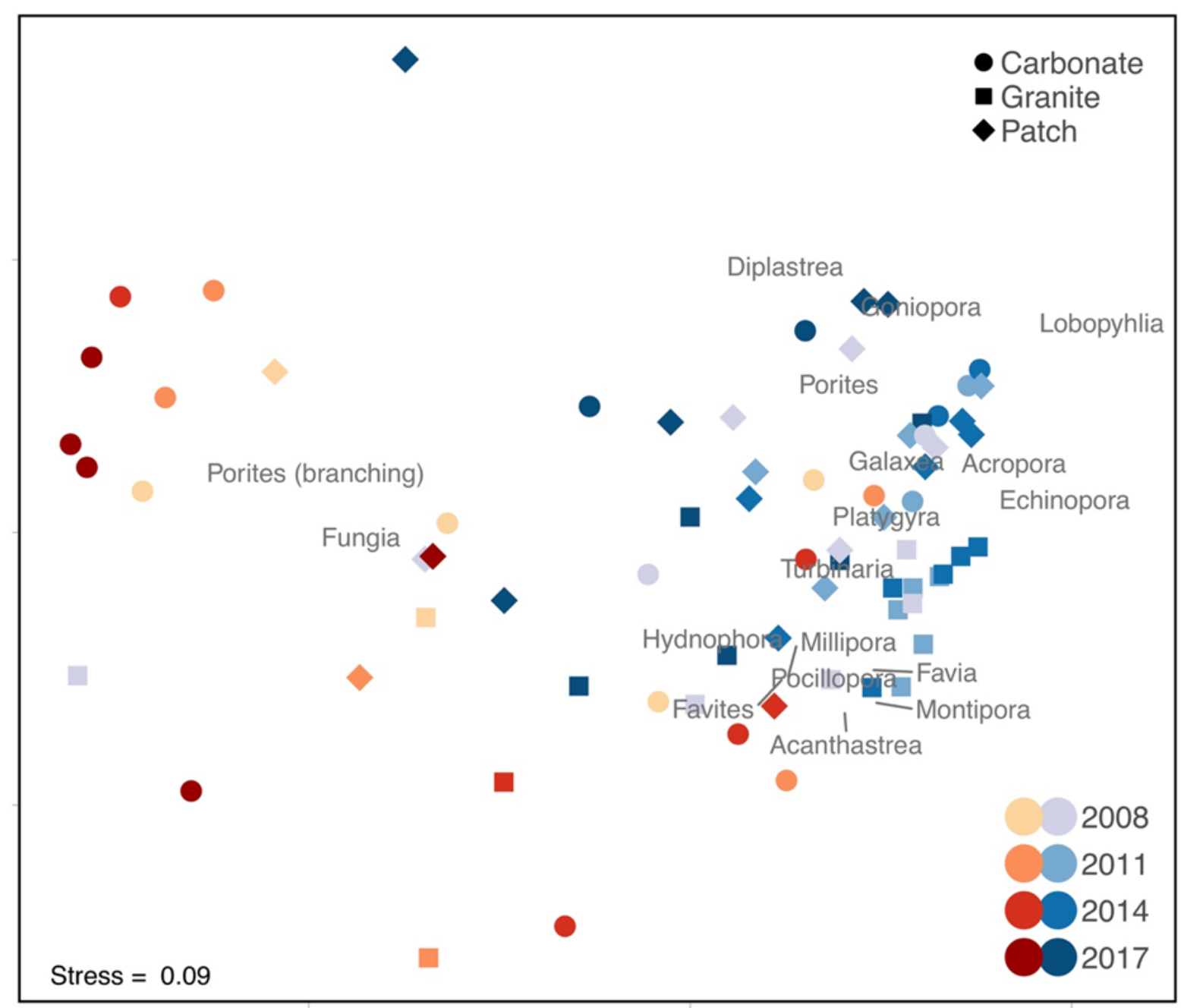

527 Fig 3. Spatial and temporal variation in coral communities. Non-metric MDS analysis of 18

528 Seychelles reefs surveyed between 2008 and 2017 displayed. Red reefs have undergone a

529 regime shift and blue reefs are recovering (Graham et al. 2015). Shading indicates survey

530 year $($ lightest $=2008$, darkest $=2017)$ and symbol shape indicates habitat type $($ carbonate $=$ 531 circles, granite $=$ squares, patch $=$ diamonds $).$ 

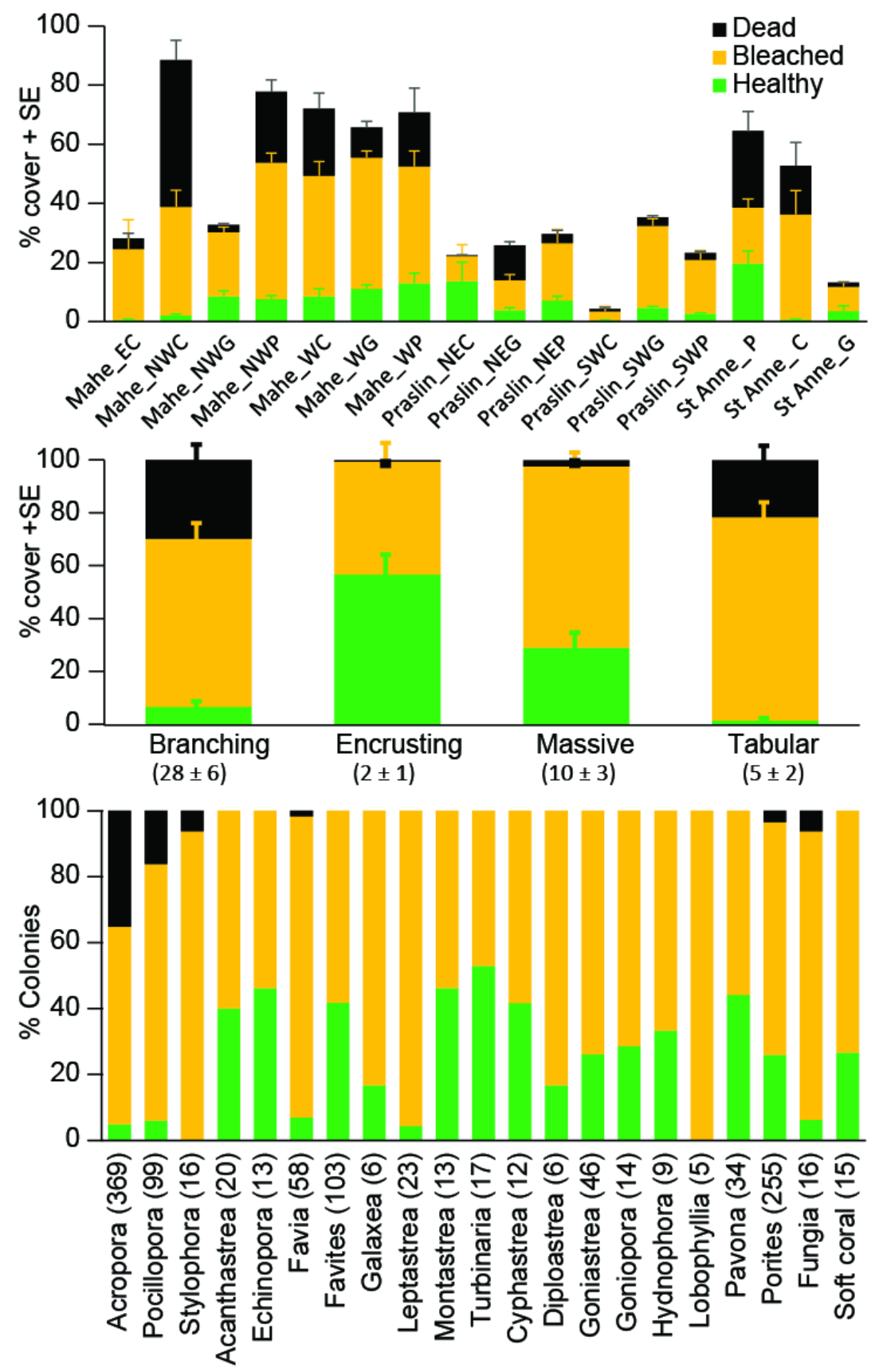

534 Fig 4. Extent of coral bleaching on 16 Seychelles reefs in May-June 2016. Means and standard errors calculated from 8 replicate counts at each reef. Likelihood ratio tests indicated significant spatial variation in bleaching $(\mathrm{P}<0.001)$, dead coral $(\mathrm{P}<0.001)$, and healthy coral $(\mathrm{P}<0.001)$. Bleaching also varied among corals of different morphology and genera.

538 The number of colonies surveyed within each genera is in parentheses. 

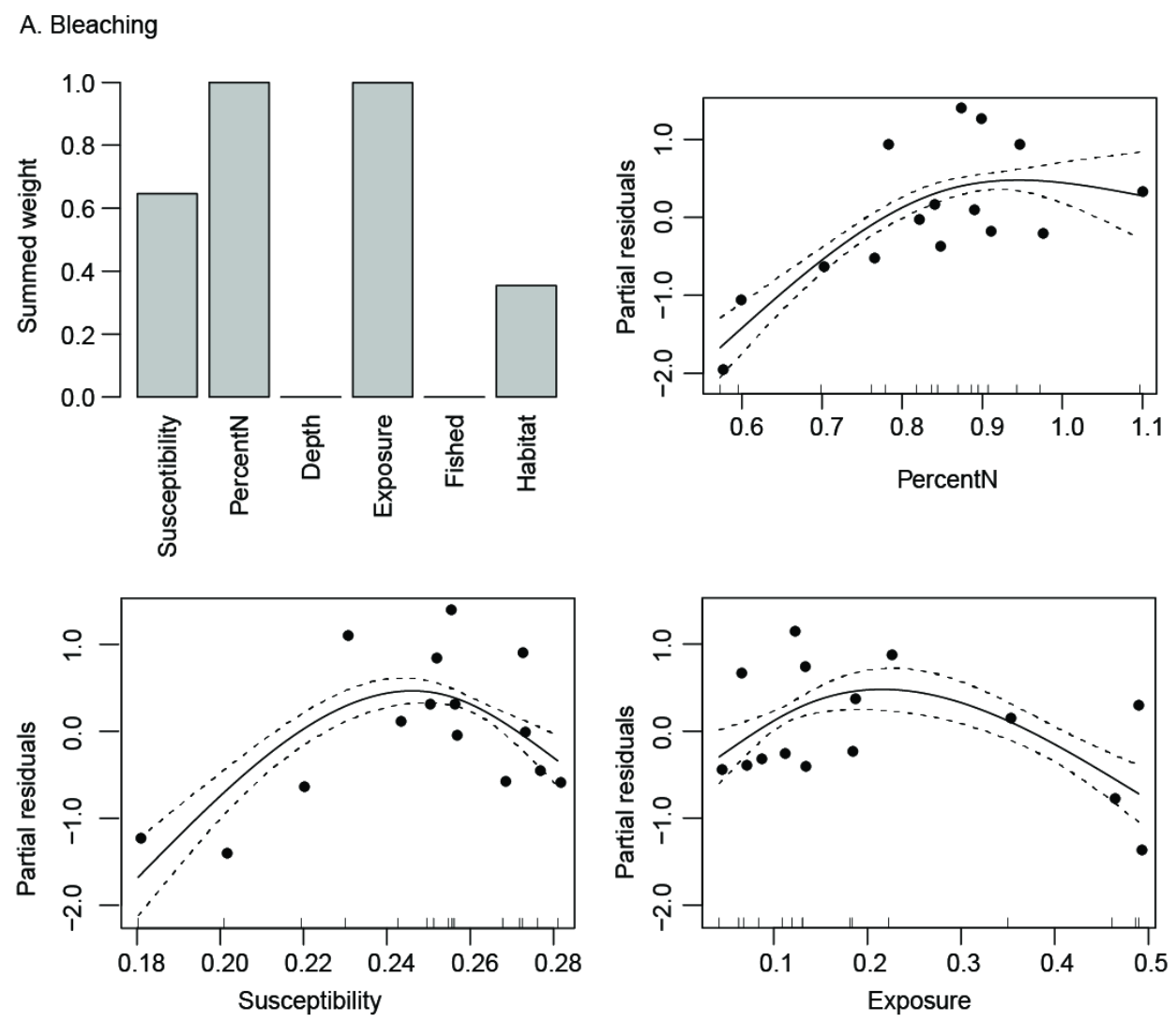

B. Mortality
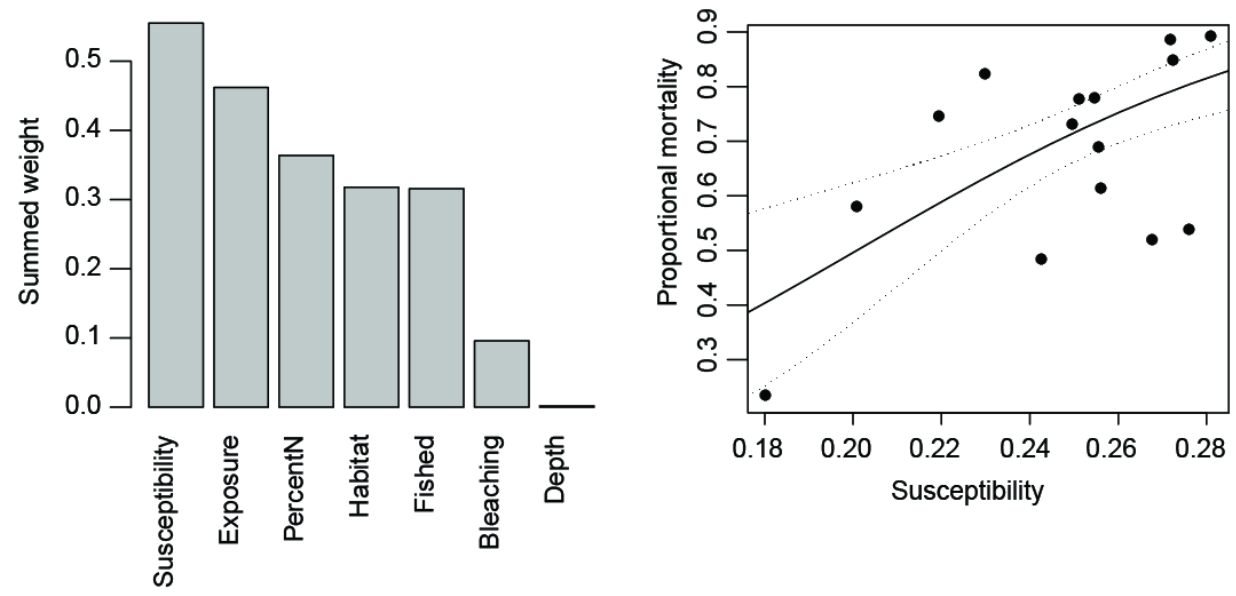

540

541 Fig 5. Relative importance of environmental variables in predicting the extent of coral A.

542 bleaching and B. mortality at 15 Seychelles reefs following 2016 heat stress. The

543 relationships for the best models, with 95\% confidence intervals (dotted lines), are plotted. 

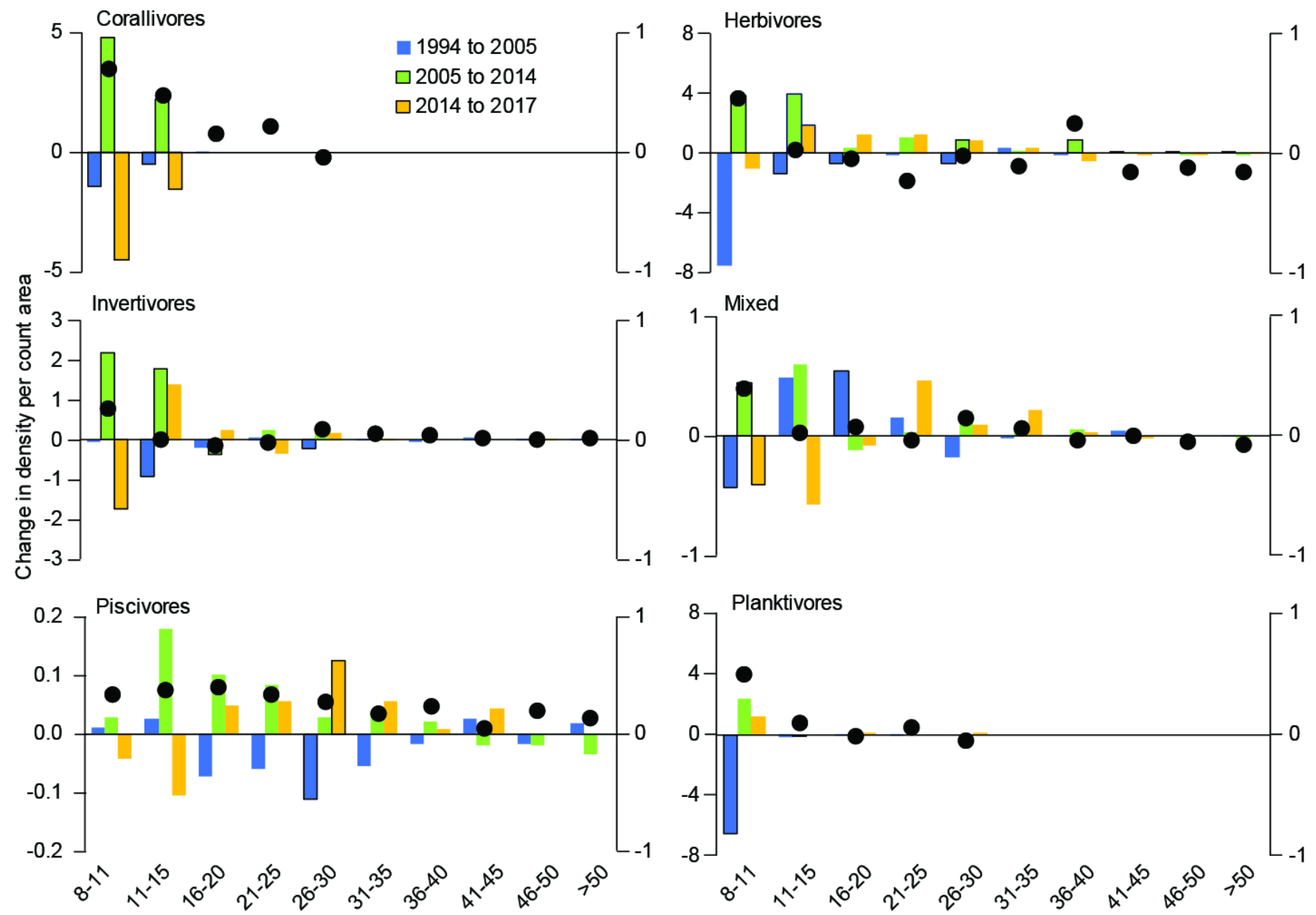

Size class category $\mathrm{TL}(\mathrm{cm})$

547 Fig 6. Shifts in fish abundance during periods of branching coral cover decline (1994 to 2005 and 2014 to 2017) and recovery (2005 to 2014). Each bar represents the average change in

549 fish density (left axis) per count area $\left(154 \mathrm{~m}^{2}\right)$ from 18 reefs consistently surveyed over the

550 three time periods. Bars with a black outline denote significant changes in density based on

$55195 \%$ confidence intervals. Dots are correlation coefficients for the relationship between

552 abundance of fish within each dietary size category and percent cover of branching coral

553 (right axis). 